IRSTI: 44.31 .31

\title{
Modeling of low-grade pulverized coal combustion
}

\author{
Safarik P. \\ Thermodynamics and Fluid Dynamics Department, \\ Czech Technical University in Prague, Prague, Czech Republic \\ e-mail: pavel.safarik@fs.cvut.cz
}

\begin{abstract}
The article is devoted to the complex research processes of heat and mass transfer occurring in the real conditions of solid fuel (coal) combustion. Development of technological processes with economic and ecological advantages are the main purpose for many researches in thermal physics and technical physics. The complex processes of heat and mass transfer in the presence of combustion are non-stationary, strongly non-isothermal with a constant change in the physical and chemical state of the environment. It greatly complicates their experimental study. In this case, studying of heat and mass transfer in highreacting media with simulation of physical and chemical processes occur during combustion of pulverized coal is important for the solution of modern power engineering industry and ecology problems. In this regard, a comprehensive study of heat and mass transfer processes at high-temperature media observed. Investigations based on the achievements of modern physics by using numerical methods for 3D modeling. Numerical experiments are conducted to describe and study aerodynamic characteristics, heat and mass transfer processes during the burning of pulverized Kazakhstan low-grade coal. The results obtained are of great practical importance, since they allow us to develop recommendations for the improvement and design of new combustion chambers and burners, and also can be useful in optimizing the whole process of burning fossil fuels.
\end{abstract}

Keywords: aerodynamic, combustion, heat exchange, numerical experiment PACS numbers: 47.70.Pq; 82.33.Vx; 88.20.jj; 07.05.Tp; 47.50.Cd.

\section{Introduction}

Solid fuel combustion is a complex physical and chemical phenomenon, which occurs at high temperatures with rapid and complete oxidation of combustible matter (carbon) by atmospheric oxygen and accompanied by a large amount of heat release [1-2]. Due to the low quality of main Kazakh coal deposits their exploitation at industry has increased scientific and applied relevance. Conducting of deep research on coal combustion in the real conditions can ensure the efficient technological process at all [3-5]. Heightened interest observed in particular to the study of heat and mass transfer processes at combustion of pulverized Kazakh coal with high ash content [6-7]. As it known combustion processes take place under conditions of strong turbulence and non-isothermal flow, multiphase medium with a significant impact of nonlinear effects of thermal radiation, interfacial interaction and multistage proceeding with chemical reactions [8-9]. Such phenomena have an important role in studying of the natural phenomenon of low-grade coal combustion. So investigations of turbulent chemically reacting media are extremely important to deepen knowledge of physical and chemical properties, for application possibilities.

In the context of depletion of natural energy resources and environmental pollution rational use of energy fuel, increasing the efficiency of energy generation and solution of environmental problems are urgent and important task to solve. Development of technological processes with economic and ecological advantages are the main purpose for many researches in this area. The complex processes of heat and mass transfer in the presence of combustion are non-stationary, strongly nonisothermal with a constant change in the physical and chemical state of the environment. It greatly complicates their experimental study. In this case, studying of heat and mass transfer in high-reacting media with simulation of physical and chemical processes occur during combustion of pulverized coal is important for the solution of modern power engineering industry and ecology problems. In this regard, a comprehensive study of heat and mass 
transfer processes at high-temperature media observed. Investigations based on the achievements of modern physics by using numerical methods for $3 \mathrm{D}$ modeling [10-15] that in turn do not need labor force also much time. Applying of computational technology allow us to describe the actual physical processes that occur during combustion of energy fuel as accurate as possible. Finally, it has been put the objective of this paper oriented on holding numerical experiments on studying heat and mass transfer processes occurring in the areas of real geometry of the combustion chamber during the burning of energy fuel. It has been established mathematical model of physical-chemical combustion process.

\section{Materials and methods}

Study of processes of heat and mass transfer during coal combustion is possible only based on a complete theory of combustion physics. It includes a wide range of physical and chemical effects and its formulation of a mathematical model. For the simulation of heat and mass transfer in the presence of physical and chemical processes are used the fundamental laws of conservation of mass, momentum, energy [16-19]. Heat and mass transfer processes in the presence of physical and chemical transformations - is the interaction of turbulent flows. Therefore, the chemical processes here should take into account the law of conservation of components of the reacting mixture, multiphase medium, its turbulence degree, heat generation due to the radiation of heated fluid and chemical reactions. The law of conservation of substance written in the form of the law of conservation of matter as follows:

$$
\frac{\partial \rho}{\partial t}+\frac{\partial}{\partial x_{i}}\left(\rho u_{i}\right)=q_{N} .
$$

The law of conservation of momentum and the equation of motion expressed as:

$$
\frac{\partial}{\partial t}\left(\rho u_{i}\right)=-\frac{\partial}{\partial x_{j}}\left(\rho u_{i} u_{j}\right)+\frac{\partial \tau_{i j}}{\partial x_{j}}-\frac{\partial P}{\partial x_{i}}+\rho f_{i}
$$

Law of energy conservation:

$$
\begin{gathered}
\frac{\partial}{\partial \mathrm{t}}(\rho \mathrm{h})=-\frac{\partial}{\partial \mathrm{x}_{\mathrm{i}}}\left(\rho \mathrm{u}_{\mathrm{i}} \mathrm{h}\right)- \\
-\frac{\partial \mathrm{q}_{\mathrm{i}}^{\mathrm{res}}}{\partial \mathrm{x}_{\mathrm{j}}}+\frac{\partial \mathrm{P}}{\partial \mathrm{t}}+\mathrm{u}_{\mathrm{i}} \frac{\partial \mathrm{P}}{\partial \mathrm{x}_{\mathrm{i}}}+\tau_{\mathrm{ij}} \frac{\partial \mathrm{u}_{\mathrm{j}}}{\partial \mathrm{x}_{\mathrm{i}}}+\mathrm{S}_{\mathrm{h}}
\end{gathered}
$$

The conservation law for the components of the reaction mixture:

$$
\frac{\partial}{\partial \mathrm{t}}\left(\rho \mathrm{C}_{\beta}\right)=-\frac{\partial}{\partial \mathrm{x}_{\mathrm{i}}}\left(\rho \mathrm{C}_{\beta} \mathrm{u}_{\mathrm{i}}\right)+\frac{\partial \mathrm{j}_{\mathrm{i}}}{\partial \mathrm{x}_{\mathrm{i}}}+\mathrm{S}_{\beta} .
$$

For technical flames, it takes into account the transfer of matter only by diffusion. Transfer of substance due to the pressure gradient, the action of external forces (electric and magnetic fields) and thermal diffusion are small and they be neglected. Then the last equation written as follow:

$$
\frac{\partial}{\partial \mathrm{t}}\left(\rho \mathrm{C}_{\beta}\right)=-\frac{\partial}{\partial \mathrm{x}_{\mathrm{i}}}\left(\rho \mathrm{C}_{\beta} \mathrm{u}_{\mathrm{i}}\right)+\frac{\partial}{\partial \mathrm{x}_{\mathrm{i}}}\left(\frac{\mu_{\text {eff }}}{\sigma_{\beta \text { eff }}} \frac{\partial \mathrm{C}_{\beta}}{\partial \mathrm{x}_{\mathrm{i}}}\right)+\mathrm{S}_{\beta} .
$$

In this paper for modeling of turbulence flows used the standard k- $\varepsilon$ turbulence model, excluding the effect of lift or "twist" of flow, which is represented by the equation of turbulent kinetic energy transfer:

$$
\frac{\partial(\bar{\rho} \mathrm{k})}{\partial \mathrm{t}}=-\frac{\partial\left(\bar{\rho} \overline{\mathrm{u}}_{\mathrm{j}} \mathrm{k}\right)}{\partial \mathrm{x}_{\mathrm{j}}}+\frac{\partial}{\partial \mathrm{x}_{\mathrm{j}}}\left[\frac{\mu_{\mathrm{eff}}}{\sigma_{\mathrm{k}}} \frac{\partial \mathrm{k}}{\partial \mathrm{x}_{\mathrm{j}}}\right]+\mathrm{P}-\bar{\rho} \cdot \varepsilon .
$$

And the equation of dissipation (turbulent kinetic energy conversion into internal) turbulent kinetic energy $\varepsilon$ :

$$
\begin{aligned}
\frac{\partial(\bar{\rho} \varepsilon)}{\partial \mathrm{t}}= & -\frac{\partial\left(\bar{\rho} \overline{\mathrm{u}}_{\mathrm{j}} \varepsilon\right)}{\partial \mathrm{x}_{\mathrm{j}}}+\frac{\partial}{\partial \mathrm{x}_{\mathrm{j}}}\left[\frac{\mu_{\mathrm{eff}}}{\sigma_{\varepsilon}} \frac{\partial \varepsilon}{\partial \mathrm{x}_{\mathrm{j}}}\right]+\cdot \\
& +\mathrm{C}_{\varepsilon, 1} \cdot \frac{\varepsilon}{\mathrm{k}} \cdot \mathrm{P}-\mathrm{C}_{\varepsilon, 2} \cdot \frac{\varepsilon^{2}}{\mathrm{k}} \cdot \bar{\rho}
\end{aligned}
$$

Here the kinetic energy production:

$$
\mathrm{P}=\left[\mu_{\text {turb }} \cdot\left(\frac{\partial \overline{\mathrm{u}_{\mathrm{i}}}}{\partial \mathrm{x}_{\mathrm{j}}}+\frac{\partial \overline{\mathrm{u}_{\mathrm{j}}}}{\partial \mathrm{x}_{\mathrm{i}}}\right)-\frac{2}{3} \cdot \rho \cdot \mathrm{k} \cdot \delta_{\mathrm{ij}}\right] \cdot \frac{\partial \overline{\mathrm{u}_{\mathrm{i}}}}{\partial \mathrm{x}_{\mathrm{j}}} .
$$


And the rate of dissipation of turbulent energy:

$$
\bar{\rho} \varepsilon=\overline{\mu_{\text {turb }} \cdot \frac{\partial \mathrm{u}_{\mathrm{i}}^{\prime}}{\partial \mathrm{x}_{\mathrm{j}}} \cdot\left(\frac{\partial \mathrm{u}_{\mathrm{i}}^{\prime}}{\partial \mathrm{x}_{\mathrm{j}}}+\frac{\partial \mathrm{u}_{\mathrm{j}}^{\prime}}{\partial \mathrm{x}_{\mathrm{i}}}\right)} .
$$

If $\mathrm{k}$ and $\varepsilon$ are known, the turbulent viscosity determined by the Prandtl-Kolmogorov relationship as: $\mu_{\text {turb }}=\mathrm{c}_{\mu} \rho \mathrm{k}^{2} / \varepsilon$.

Empirical constants $c_{\mu}=0.09 ; \sigma_{k}=1.00 ; \sigma_{\varepsilon}=$ $1.30 ; \quad C_{\varepsilon 1}=1.44 ; \quad C_{\varepsilon 2}=1.92$ determined experimentally. For the turbulent numbers of Prandtl and Schmidt were taken as 0.9.

A generalized equation of the transport value in a turbulent flow will then be:

$$
\frac{\partial}{\partial \mathrm{t}}(\rho \Phi)=-\frac{\partial}{\partial \mathrm{x}_{\mathrm{j}}}\left(\rho \mathrm{u}_{\mathrm{i}} \Phi\right)+\frac{\partial}{\partial \mathrm{x}_{\mathrm{j}}}\left[\Gamma_{\phi, \text { eff }} \frac{\partial \Phi}{\partial \mathrm{x}_{\mathrm{j}}}\right]+\mathrm{S}_{\phi} .
$$

To avoid mistakes that can lead to a physically meaningless result, an adequate initial and boundary conditions corresponding to real physical process given. As an object of research chosen the combustion process of Kazakh coal in combustion chamber of the real energy facility (boiler BKZ-75 of Shakhtinsk TPS in Kazakhstan). All conditions taken into account of the real process of fuel combustion. For conducting numerical modeling were used control volume method [26-27], where in computational experiment the chamber has been divided into 126496 cells.

\section{Results of numerical modeling}

Following shown results of three-dimensional modeling of heat and mass transfer processes during combustion of pulverized low-grade coal in real conditions of combustion chamber of boiler. Aerodynamic pattern of motion of two-phase turbulent flow of pulverized coal combustion causes the heat and mass transfer process in general [2830]. Figure 1 shows a two-dimensional graph of the full velocity vector, determined by the relationship: $\vec{V}=\sqrt{\mathrm{U}^{2}+\mathrm{V}^{2}+\mathrm{W}^{2}}$. In the direction of camera output speed of flows decreased. The peak area values with maximum speed is clearly visible, which is equal to about $20 \mathrm{~m} / \mathrm{s}$. There at 4 meters by height of chamber located the combustor burners, and fed the fuel and oxidant mixture into the camera at maximum speed. Distribution character of flow velocity in height due to the vortex transfer of reacting medium and depending on the geometrical design of the chamber at all. At the outlet of chamber, it seen that velocity has a maximum value $8.76 \mathrm{~m} / \mathrm{s}$ at section $\mathrm{X}=7.0 \mathrm{~m}$ and an average value not exceeding the $5 \mathrm{~m} / \mathrm{s}$ by height.

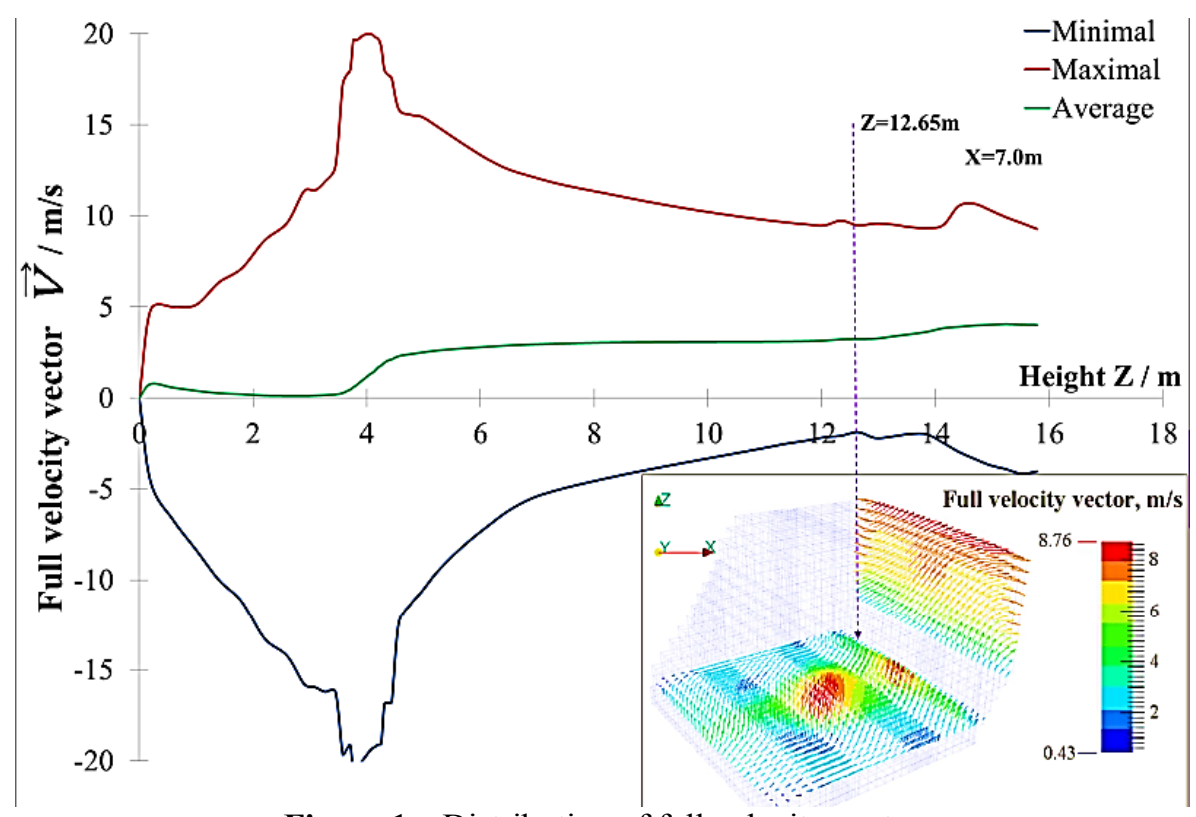

Figure 1 - Distribution of full velocity vector 
Figure 2 shows the distribution of maximum, minimum and average values of the temperature field in the combustion chamber. There is also observed a sharp decrease in the temperature of fuel feeding zone. This is because the fuel supplied by a lower temperature. It can be seen that temperature values reach their maximum values in the area below a girdle of the burners where located torch core (approximately at 3 meters). This is because in this area the eddy currents (from installed four burners: on 2 burners on two opposite tiers) have a maximum convective transfer that increases the residence time of coal particles in here. As a result, in this area observed temperature rise to $\sim 1370{ }^{\circ} \mathrm{C}$. In addition, at the output of the chamber maximum value of temperature is about $900-950{ }^{\circ} \mathrm{C}$. This clearly seen from the $3 \mathrm{D}$ picture placed in the right corner of the figure. In the figure also presented the point of the theoretically calculated value of the temperature of exhaust gases in the output of the chamber defined according to the normative method of thermal calculation [31] and data from the natural experiments held in real TPP of RK [32].

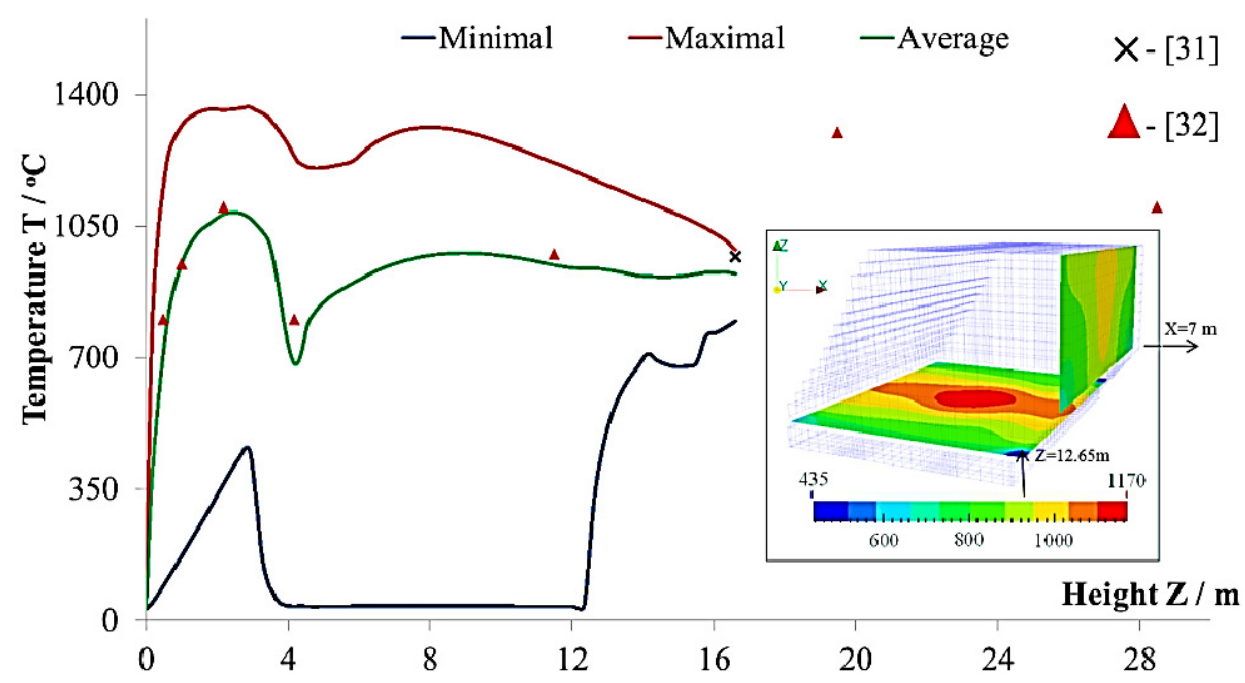

Figure 2 - Temperature distribution and verification with experimental data

The method of thermal calculation in power engineering is still the most reliable for finding the temperature at the outlet of the combustion chamber. It is seen that the difference between the results of numerical calculation is small and is only $4.7 \%$. This proves that the method of $3 \mathrm{D}$ modeling gives good description of real processes of heat and mass transfer of fuel combustion. The verification results show the good conformity with calculated results.

Figure 3 and 4 shows the results of 3D modeling of carbon dioxide $\mathrm{CO}_{2}$ concentration distributions. Carbon mono oxide $\mathrm{CO}$ reacts with oxygen completely and so formed its dioxide $\mathrm{CO}_{2}$. Concentrations of carbon dioxide $\mathrm{CO}_{2}$ have their largest amount at the top areas of chamber (section $\mathrm{Y}=3.19 \mathrm{~m}$ ). And the minimal values are observed at the region, where the burner equipment is set. From the figure 6 at the section $Y=3.19 \mathrm{~m}$ it is seen that concentration of carbon dioxide $\mathrm{CO}_{2}$ has the minimal value equal to $0.0089 \mathrm{~kg} / \mathrm{kg}$. In addition, in average it raised to $\sim 0.13 \mathrm{~kg} / \mathrm{kg}$ at the $Z=12.65 \mathrm{~m}$ section by height and $\sim 0.15 \mathrm{~kg} / \mathrm{kg}$ at the outlet of the chamber (section $\mathrm{X}=7.0 \mathrm{~m}$ ).

These concentration distributions of carbon dioxide verified with the known data as shown in Fig. 8.

Concentrations of carbon dioxide $\mathrm{CO}_{2}$ are in a good agreement with experimental data, received from real thermal power plant equipment [32]. By comparisons of numerical experiment results held in this work with natural data from TPP, it noticed that the difference is for carbon dioxide $\mathrm{CO}_{2}$ is $4 \%$. So, considering results obtained in this paper we can propose the observed method of research of combustion processes is reliable and valid sufficiently to be useful in studying of low-grade coal combustion technological processes in energy objects. 

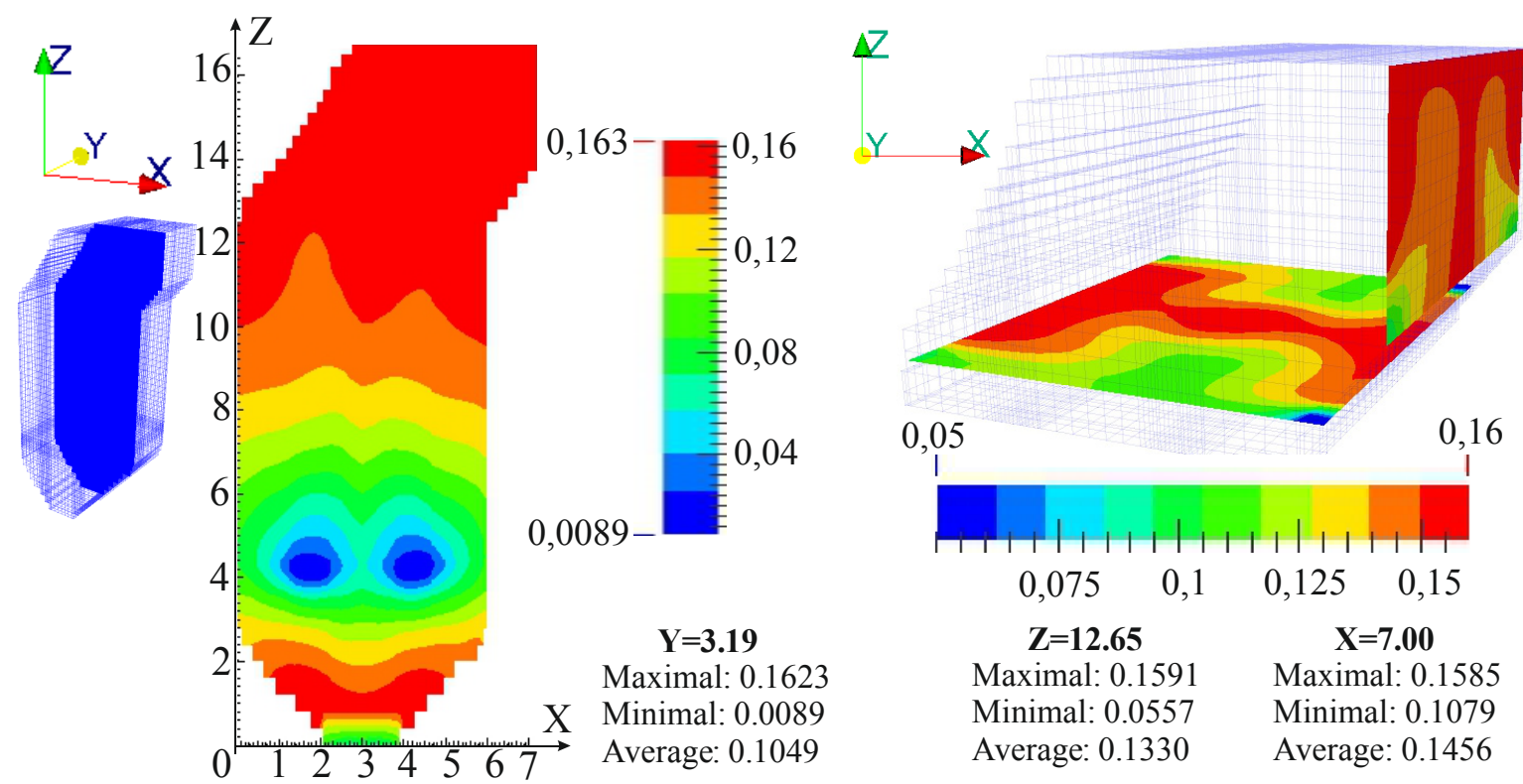

Figure 3-3D distribution of the carbon dioxide concentrations on sections of the chamber

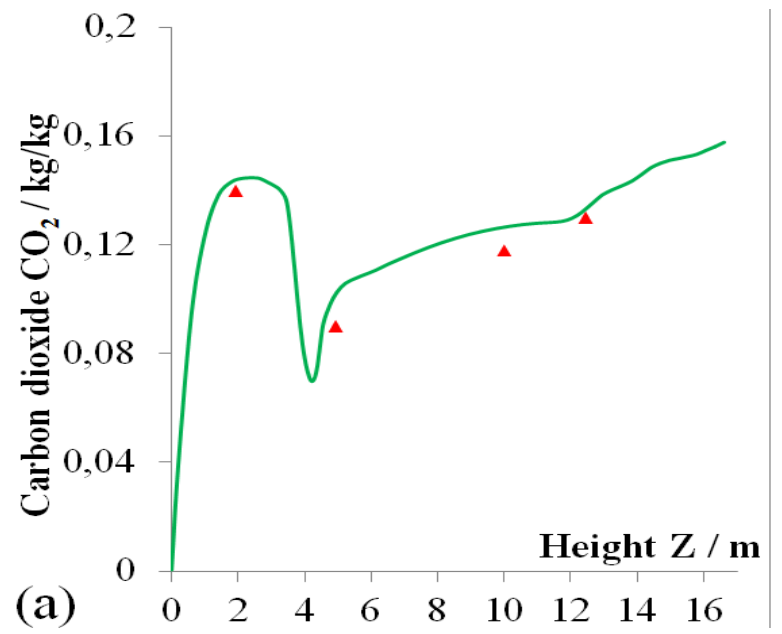

Figure 4 - Verification of calculation results with experimental data [32]

\section{Conclusions and perspectives}

In conclusion, with computational research of combustion and modeling of heat and mass transfer processes determined velocity characteristics of turbulent flows, their turbulent kinetic energy and dissipation energy. Aerodynamic characteristics shows that intensive mixing of fuel and oxidant held in the central part of the chamber. In addition, it caused the increasing of temperature values to $1370^{\circ} \mathrm{C}$ in core of torch and monotonically decreased to $922^{\circ} \mathrm{C}$ at the outlet. Formation of hazardous substances as carbon oxides $\left(\mathrm{CO}_{2}\right)$ are depends on their chemical interaction with oxygen. Carbon dioxide has its maximal values at the outlet of the chamber $(\sim 0.16 \mathrm{~kg} / \mathrm{kg})$. Obtained results of numerical experiments have great theoretical and practical importance, as it will allow improve the design of combustion chambers and burners, to optimize the process of burning of high-ash content energy coal of Kazakhstan Republic. 


\section{References}

1. F. Williams. Combustion theory. - California: Westview Press, 1985. - 704 p.

2. S.J. Zarrouk, M.J. O'Sullivan, J.D. St George. Modeling the spontaneous combustion of coal: the adiabatic testing procedure // Combustion theory and modeling. - 2006. - Vol. 10. - P. 907-926.

3. V. Kez, J.L. Consalvi, F. Liu, etc. Assessment of several gas radiation models for radiative heat transfer calculations in a three-dimensional oxy-fuel furnace under coal-fired conditions // International journal of thermal sciences. - 2018. - Vol. 120. - P. 289-302.

4. H.D. Wu, W. Han, D.D. Wang, etc. A carbon oxidation factor regression model of coal-fired power plants in China // Journal of cleaner production. - 2018. - Vol. 142. - P. 4403-4411.

5. A. Askarova, S. Bolegenova, etc. Influence of boundary conditions to heat and mass transfer processes // International journal of mechanics. - 2016. - Vol.10. - P. 320-325.

6. A. Askarova, S. Bolegenova, P. Safarik, V. Maximov, M. Beketayeva. Numerical modeling of pulverized coal combustion at thermal power plant boilers // Journal of thermal science. - 2015. - Vol. 24, issue 3. - P. $275-282$.

7. R. Leithner, H. Müller, A. Magda, etc. Combustion of low-rank coals in furnaces of Kazakhstan coal-firing power plants // VDI Berichte. - 2007. - Vol. 1988. - P. 497-502.

8. Ch.K. Law. Combustion physics. - Cambridge: Cambridge University Press, 2006. - 742 p.

9. W. Xu, L. Kun. Analysis of pulverized coal flame stabilized in a 3D laminar counter flow // Combustion and flame. - 2018. - Vol. 189. - P. 106-125.

10. L. Wieckowski, P. Krawczyk, K. Badyda. Numerical investigation of temperature distribution in the furnace of a coal fired grate boiler in part load conditions // Journal of power technologies. - 2017. - Vol. 97, Issue. 5. - P. 359365 .

11. E.I. Heierle, R. Manatbayev, etc. CFD study of harmful substances production in coal-fired power plant of Kazakhstan // Bulgarian chemical communications. - 2016. - Vol. 48, Special Issue E. - P. 260-265.

12. J. Lazar, N. Haugen, J. Kruger, etc. Numerical study of hydrogen inhibition of char gasification using Detailed hetero- and homogeneous chemical kinetics // Energy \& fuels. - 2016. - Vol. 30, Issue. 6. - P. 4411-4418.

13. M. Buchmayr, J. Gruber, etc. A computationally inexpensive CFD approach for small-scale biomass burners equipped with enhanced air staging // Energy conversion and management. - 2016. - Vol. 115. - P. 32-42.

14. Z.L. Zhao, H.Q. Tang, Q. Quan, etc. Simulation study on performance of novel oxygen-coal lances for pulverized coal combustion in blast furnace Tuyere new paradigm of particle science and technology // Procedia Engineering. - 2015. -Vol. 102. - P. 1667-1676.

15. B. Taraba, Z. Michalec, V. Michalcova, etc. CFD simulations of the effect of wind on the spontaneous heating of coal stockpiles // Fuel. - 2014. -V. 118. - P. 107-112.

16. H. Muller. Numerische Simulation von Feuerungen. - Braunschweig: IWBT, 1997. -85 p. (in German)

17. R. Leithner, H. Müller CFD studies for boilers // Second M.I.T. conference on computational fluid and solid mechanics. - Cambridge, 2003. - 172 p.

18. B. Launder, D. Spalding. The numerical computation of turbulent flows // Computer Methods in Applied Mechanics and Engineering. - 1974. - Vol. 3. - P. 269-289.

19. L. El-Mahallawy, S. El-Din Habik. Fundamentals and technology of combustion. - Oxford: Elsevier science: Energy, 2002. -839 p.

20. A. De Marco, F. Lockwood. A new flux model for the calculation of radiation furnaces // Italian flame days. 1975. - P. 1-13.

21. G. Choubey, K.M. Pandey. Effect of variation of inlet boundary conditions on the combustion flow-field of a typical double cavity scramjet combustor // International journal of hydrogen energy. - 2018. - Vol. 43. - P. 81398151.

22. W. Adamczyk, K. Myohanen, T. Hyppanen, etc. Generation of data sets for semi-empirical models of circulated fluidized bed boilers using hybrid Euler-Lagrange technique // Energy. - 2018. - Vol. 143. - P. 219-240.

23. G.X. Li, F.S. Gu, T. Wang, etc. Investigation into the dynamic response of cylinder liners in an IC engine based on a validated finite-element model // Systems science \& control engineering. - 2017. - Vol. 5, Issue. 1. - P. 56-69.

24. P. Benard, G. Balarac, V. Moureau, etc. Mesh adaptation for large-eddy simulations in complex geometries // International journal for numerical methods in fluids. - 2016. - Vol. 81, Issue. 12. - P. 719-740.

25. J.W. Mitchell, J.M. Tarbell. A kinetic model of nitric oxide formation during pulverized coal combustion // AIChE Jornal. - 1982. - Vol. 28. - P. 302-320.

26. H. Ali, E. Askri, S. Ben Nasrallah. Comparative study of WSGG and SLW models coupled with control volume finite element method for no gray radiation prediction // International journal of thermal sciences. - 2017. Vol. 113. - P. 73-82.

27. P. Madejski, D. Taler, J. Taler. Numerical model of a steam superheater with a complex shape of the tube cross section using control volume based finite element method // Energy conversion and management. - 2016. - Vol. 118. P. 179-192. 
28. A.A. Bhuiyan, M.R. Karim, J.T. Hart, etc. Investigation of slot-burner aerodynamics with recessed-type nozzle geometry // Fluids. - 2016. - Vol. 1, Issue. 2. - P. 10-15.

29. S.V. Alekseenko, I.S. Anufriev, V.G. Glavniy, D.V. Krasinsky, etc. Study of 3D flow structure and heat transfer in a vortex furnace // Heat transfer research. - 2016. - Vol. 47, Issue. 7. - P. 653-667.

30. A. Bhuiyan, J. Naser, etc. Effects of geometric parameters for wavy finned-tube heat exchanger in turbulent flow: a CFD modeling // Frontiers in heat and mass transfer. - 2015. - Vol. 6. - P. 013005.

31. Teplovoi raschet kotlov: Normativnyi metod. - SPb.: NPO CKTI, 1998. - 256 p. (in Russian)

32. B.K. Aliyarov, M.B. Aliyarova Szhiganiye kazakhstanskikh ugley na TES i na krupnykh kotelnykh: opyt i perspektivy. - Almaty: Gylym ordasy, 2011. - 304 p. (in Russian). 